\title{
A Stable Ruthenium Catalyst for Productive Olefin
}

\section{Metathesis}

Grant S. Forman,${ }^{*} a$ Ann E. McConnell, ${ }^{a}$ Martin J. Hanton, ${ }^{a}$ Alexandra M. Z. Slawin, ${ }^{b}$ Robert P. Tooze, ${ }^{a}$ Werner Janse van Rensburg, ${ }^{c}$ Wolfgang H. Meyer, ${ }^{c}$ Cathy Dwyer, ${ }^{c}$ Megan M. Kirk ${ }^{c}$ and D. Wynand Serfontein ${ }^{c}$

${ }^{a}$ Sasol Technology Research Laboratory, St Andrews

Sasol Technology (UK) Limited, Purdie Building, North Haugh

St Andrews, Fife, KY16 9ST, Scotland, U.K.

Corresponding Author. E-mail: grant.forman@sasol.com

${ }^{b}$ School of Chemistry, University of St Andrews

Purdie Building, North Haugh, St Andrews, Fife, KY16 9ST, Scotland, U.K.

Fax: +44 (0) 1334463 384; Tel: +44 (0) 1334467280

E-mail: amzs@st-andrews.ac.uk.

${ }^{c}$ Sasol Technology Research \& Development

PO Box 1, Klasie Havenga Road, Sasolburg, 1947, South Africa

Fax: +27 11 5223593; Tel: +27 169604443.

E-mail: wolfgang.meyer@sasol.com 


\section{Supporting Information}

\section{Experimental Section}

General Procedures. Manipulations of organometallic compounds were performed using standard Schlenk techniques under an atmosphere of dry argon or in a nitrogen-filled mBraun Unilab 3702 Glovebox $\left(\mathrm{O}_{2}<1 \mathrm{ppm}\right)$. All reactions were conducted in oven- $\left(150{ }^{\circ} \mathrm{C}\right)$ dried glassware. Kugelrohr distillations were performed using a Büchi B-580 Glass Oven. NMR spectra were recorded on either a Bruker Avance $300 \mathrm{MHz}$ or a Varian Unity Plus $500 \mathrm{MHz}$ spectrometer. Unless otherwise stated, ${ }^{31} \mathrm{P}$ NMR were referenced using $\mathrm{H}_{3} \mathrm{PO}_{4}(\delta=0 \mathrm{ppm})$ as an internal standard. Mass Spectrometry was performed using a Waters ZMD single quadrupole mass spectrometer using elctrospray ionisation for low resolution analysis and a Bruker Apex III FT-ICR Mass Spectrometer using an Apollo Electrospray source for high resolution analysis. Gas chromatography was performed on an Agilent Technologies 6890N Network GC system using either a Pona column for non-polar samples or a MDN column for polar samples.

Materials and Methods. Toluene, tetrahydrofuran, diethyl ether and hexanes were dried by passage through an Innovative Technologies solvent purification system. AR grade methylene chloride and pentane were purchased from Aldrich chemicals and degassed before use. Ruthenium complex $\mathbf{4}^{1}$ was prepared according to literature procedures. Ruthenium complexes $\mathbf{1}$ and $\mathbf{2}$ were obtained from Strem or Aldrich Chemicals. Aluminium oxide chromatography was driven with argon and performed with aluminium oxide (activated, neutral) Brockmann I; standard grade, CA. 150 mesh obtained from Aldrich chemicals. The progress of the chromatography was monitored visually (purple band on column), and the presence of the catalyst in fractions of eluant is evident by simple visual inspection. 
3a and 3b: A 3-neck round bottomed flask equipped with pressure-equalizing dropping funnel and reflux condensor was charged with degassed 1,5-cyclooctadiene (4.66 g, $43.1 \mathrm{mmol})$ and cyclohexylphosphine $(5.25 \mathrm{~g}, 45.2 \mathrm{mmol})$ and heated to $105{ }^{\circ} \mathrm{C}$. A solution of $1,1^{\prime}$ azobis(cyclohexanecarbonitrile) $(3.0 \mathrm{~g}, 12.3 \mathrm{mmol})$ in toluene $(20 \mathrm{~mL})$ was added dropwise to the vigorously stirred solution over 2 hours and the solution heated at $105^{\circ} \mathrm{C}$ for a further 21 hours. After such time a further portion of 1,1'-azobis(cyclohexanecarbonitrile) $(0.5 \mathrm{~g}, 2 \mathrm{mmol})$ was added as a solid to the reaction mixture and heating was continued at $105{ }^{\circ} \mathrm{C}$ for an additional 8 hours. After this time the volatiles were removed under vacuum to leave a viscous, pale yellow oil. The oil was subjected to a short-path distillation (fraction distilling at $>96^{\circ} \mathrm{C}$ collected) to leave a white, waxy solid. The solid thus obtained was subjected to Kugelrohr distillation and the fraction distilling at $\sim 110^{\circ} \mathrm{C}$ was collected to provide a ca. 3:1 mixture of $\mathbf{3 a}$ and $\mathbf{3 b}$ as a waxy white solid (4.57 g, 47\% yield). ${ }^{31} \mathrm{P}\left({ }^{1} \mathrm{H}\right) \mathrm{NMR}\left(121 \mathrm{MHz}, \mathrm{C}_{6} \mathrm{D}_{6}\right): \delta=13.6$ (s, [4.2.1] isomer), -25.3 ppm (s, [3.3.1] isomer); $\mathrm{MS}(\mathrm{CI}): m / e=224.3\left[\mathrm{M}^{+}\right]$.

5: A solution of $\mathbf{3 a}$ and $\mathbf{3 b}$ (ca. 3:1, $1.49 \mathrm{~g}, 6.65 \mathrm{mmol}$ ) in $\mathrm{CH}_{2} \mathrm{Cl}_{2}(15 \mathrm{ml})$ was added to a solution of complex $4(1.69 \mathrm{~g}, 2.22 \mathrm{mmol})$ in $\mathrm{CH}_{2} \mathrm{Cl}_{2}(15 \mathrm{ml})$ and stirred at room temperature for $48 \mathrm{~h}$. After such time the solvent was removed under vacuum and pentane (40 $\mathrm{ml})$ was added. The resulting purple solid was filtered and washed with petrol $(3 \times 20 \mathrm{ml})$ to afford complex 5 as a purple powder $(1.1 \mathrm{~g}, 72 \%$ yield $) .{ }^{31} \mathrm{P}\left({ }^{1} \mathrm{H}\right) \mathrm{NMR}\left(121 \mathrm{MHz}, \mathrm{CD}_{2} \mathrm{Cl}_{2}\right): \delta=24.5(\mathrm{bs}) ;{ }^{1} \mathrm{H}$ NMR $(300$ $\left.\mathrm{MHz}, \mathrm{CD}_{2} \mathrm{Cl}_{2}\right): \delta=19.1\left(\mathrm{~d}, 1 \mathrm{H},{ }^{3} J_{\mathrm{HH}}=11.52 \mathrm{~Hz}, \mathrm{Ru}=\mathrm{CH}-\right), 8.0\left(\mathrm{~d}, 1 \mathrm{H},{ }^{3} J_{\mathrm{HH}}=11.52 \mathrm{~Hz}, \mathrm{Ru}=\mathrm{CH}-\right.$ $\left.\mathrm{C} H=\mathrm{C}(\mathrm{Me})_{2}\right), 2.44(\mathrm{~s}, 4 \mathrm{H}, \mathrm{PC} H$ of Phoban $), 2.26-0.9(\mathrm{~m}, 46 \mathrm{H}$, Phoban $H) ;{ }^{13} \mathrm{C}\left({ }^{1} \mathrm{H}\right) \mathrm{NMR}(75$ $\left.\mathrm{MHz}, \mathrm{CD}_{2} \mathrm{Cl}_{2}\right): \delta=283.2(\mathrm{~m}, \mathrm{Ru}=\mathrm{CH}-), 142.2$ (s, Ru=CH-CH-), 30.0-9.0 (Phoban ligand resonances); $\mathrm{MS}\left(\mathrm{ES}^{+}\right) m / e=653.5\left([\mathrm{M}-\mathrm{Cl}]^{+}, 20\right), 615.5$ (17), 559.5 (40), 503.5 (60); HR-ES ${ }^{+}-\mathrm{MS}$ calc for $\mathrm{C}_{33} \mathrm{H}_{58} \mathrm{P}_{2} \mathrm{RuCl}$ 653.2760420, found: 653.2740285 . 
6: Complex 1 (400 mg, $0.61 \mathrm{mmol}$ ) and a mixture of 3a and $\mathbf{3 b}$ (ca. 3:1, $326 \mathrm{mg}, 1.5 \mathrm{mmol}$ ) were combined in $\mathrm{CH}_{2} \mathrm{Cl}_{2}(10 \mathrm{~mL})$ and the reaction stirred for $48 \mathrm{~h}$ at $20^{\circ} \mathrm{C}$. After such time the mixture was reduced in volume to ca. $2 \mathrm{~mL}$ and the resulting solution was passed through a short column of aluminium oxide $\left(\mathrm{CH}_{2} \mathrm{Cl}_{2}\right)$. The progress of the aluminium oxide chromatography was monitored visually, and the product rapidly eluted as a purple band. Concentration of the appropriate fractions afforded a purple residue which was washed with pentane and sonicated for 1 minute. The solid thus obtained was filtered using a cannula filter, dried under vacuum to afford $\mathbf{6}$ as a purple microcrystalline powder (328 mg, 75\% yield). ${ }^{31} \mathrm{P}\left({ }^{1} \mathrm{H}\right) \mathrm{NMR}\left(121 \mathrm{MHz}, \mathrm{C}_{7} \mathrm{D}_{8}\right): \delta=23.27$ (bs); ${ }^{1} \mathrm{H}$ NMR $(300 \mathrm{MHz}$, $\left.\mathrm{C}_{7} \mathrm{D}_{8}\right): \delta=20.22(\mathrm{~s}, 1 \mathrm{H}, \mathrm{Ru}=\mathrm{CHPh}), 9.68$ (bs, $1 \mathrm{H}$, ortho $\mathrm{CH}$ of $\left.\mathrm{C}_{6} \mathrm{H}_{5}\right), 7.49$ (bs, $1 \mathrm{H}$, ortho $\mathrm{CH}_{\text {of }} \mathrm{C}_{6} \mathrm{H}_{5}$ ), $7.1\left(\mathrm{t}, 1 \mathrm{H},{ }^{3} \mathrm{~J}_{\mathrm{HH}}=7.6 \mathrm{~Hz}\right.$, para $\mathrm{H}$ of $\left.\mathrm{C}_{6} \mathrm{H}_{5}\right), 6.95\left(\mathrm{~m}, 2 \mathrm{H}\right.$, meta $\mathrm{H}$ of $\left.\mathrm{C}_{6} \mathrm{H}_{5}\right), 2.54$ (s, 4H, PCH of Phoban), 2.20-0.70 ppm (m, 46H, Phoban H); ${ }^{13} \mathrm{C}\left({ }^{1} \mathrm{H}\right)$ NMR $\left(75 \mathrm{MHz}, \mathrm{C}_{6} \mathrm{D}_{6}\right): \delta 294.70\left(\mathrm{~d},{ }^{2} \mathrm{~J}_{\mathrm{CH}}=6.0 \mathrm{~Hz}\right.$, $\mathrm{Ru}=\mathrm{CHC}_{6} \mathrm{H}_{5}$ ), 153.02, 133.63, 131.57, 129.70, 121.11, 47.18, 38.0-19.5 (Phoban ligand resonances); MS $\left(\mathrm{ES}^{+}\right) m / e=675.3\left([\mathrm{M}-\mathrm{Cl}]^{+}, 58\right), 583.3$ (8), 545.3 (12), 413 (25); HR-ES ${ }^{+}$-MS calc for $\mathrm{C}_{35} \mathrm{H}_{56} \mathrm{P}{ }_{2} \mathrm{RuCl}$ 675.2593900, found: 675.2583784 .

9: Complex 6 (150 mg, $0.211 \mathrm{mmol})$ was dissolved in benzene $(10 \mathrm{~mL})$ and pressurized with $d$ ethylene (ca. $1.5 \mathrm{~atm}$ ) The reaction was stirred at $50{ }^{\circ} \mathrm{C}$ for 2 hours during which time a color change from purple to brown was observed. The brown mixture was cooled to room temperature and the solvent removed under vacuum to afford a brown solid. The material obtained in this way was sonicated for 1 minute, washed with pentane $(10 \mathrm{~mL})$, filtered and dried under vacuum for $16 \mathrm{~h}$. Complex 9 was obtained as a brown powder (45 mg, 34\% yield). ${ }^{31} \mathrm{P}\left({ }^{1} \mathrm{H}\right) \mathrm{NMR}\left(121 \mathrm{MHz}, \mathrm{C}_{7} \mathrm{D}_{8}\right): \delta=$ $26.0(\mathrm{bs}) ;{ }^{2} \mathrm{H}$ NMR $\left(76.8 \mathrm{MHz}, \mathrm{C}_{6} \mathrm{H}_{6}\right): \delta=19.2\left(\mathrm{~s}, 1 \mathrm{H}, \mathrm{Ru}=\mathrm{CD}_{2}\right)$.

10: Complex 6 (150 mg, $0.211 \mathrm{mmol})$ was dissolved in benzene $(10 \mathrm{~mL})$ and pressurized with ethylene (ca. $1.5 \mathrm{~atm}$ ) The reaction was stirred at $50^{\circ} \mathrm{C}$ for 2 hours during which time a color change 
from purple to brown was observed. The brown mixture was cooled to room temperature and the solvent removed under vacuum to afford a brown solid. The material obtained in this way was sonicated for 1 minute, washed with pentane $(10 \mathrm{~mL})$, filtered and dried under vacuum for $16 \mathrm{~h}$. Complex 9 was obtained as a brown powder (56 mg, 42\% yield). ${ }^{31} \mathrm{P}\left({ }^{1} \mathrm{H}\right) \mathrm{NMR}\left(121 \mathrm{MHz}, \mathrm{C}_{7} \mathrm{D}_{8}\right): \delta=$ $26.0(\mathrm{bs}) ;{ }^{1} \mathrm{H}$ NMR $\left(76.8 \mathrm{MHz}, \mathrm{C}_{6} \mathrm{H}_{6}\right): \delta=19.2\left(\mathrm{~s}, 1 \mathrm{H}, \mathrm{Ru}=\mathrm{CH}_{2}\right)$.

SM of 1-Decene (Representative Procedure): A $250 \mathrm{~mL}$ three-necked round bottom flask was fitted with a reflux condenser, thermometer and septum. A needle was inserted through the septum and connected to a gas supply via a needle valve to ensure a slow and steady stream of argon through the reaction solution. 1-Decene $(24 \mathrm{~mL}, 0.127 \mathrm{~mol})$ was added to the reaction vessel and the reaction was heated to $60{ }^{\circ} \mathrm{C}$. Complex $6(10.0 \mathrm{mg}, 0.014 \mathrm{mmol})$ was weighed into a custom-made aluminum weighing tray and added to the reaction mixture. Samples were taken at regular intervals via syringe through the septum. Samples were analysed by GC with a Pona column.

SM of Methyl Oleate (Representative Procedure): A $50 \mathrm{~mL}$ two-necked round bottom flask was fitted with a reflux condenser, and septum. A needle was inserted through the septum and connected to a gas supply via a needle valve to ensure a slow and steady stream of argon through the reaction solution. Methyl Oleate $(6.8 \mathrm{~mL}, 20 \mathrm{mmol})$, which was purified immediately before use by passing through a short plug of alumina was added to the reaction vessel and the reaction was heated to $60{ }^{\circ} \mathrm{C}$. Tetradecane $(1.0 \mathrm{~g}$, internal standard $)$ was added and the catalyst $(0.010 \mathrm{mmol})$ was weighed and transferred into a Schlenk flask under argon. Toluene $(10 \mathrm{~mL}$, degassed) was added to the Schlenk flask and an aliquot $(1 \mathrm{~mL})$ of this stock solution was transferred to the flask. Samples were taken at regular intervals via syringe through the septum. Samples were analysed by GC with an MDN column. 
RCM of Diethyl diallylmalonate (Representative Procedure): A $250 \mathrm{~mL}$ three-necked round bottom flask was fitted with a reflux condenser, thermometer and septum. A needle was inserted through the septum and connected to a gas supply via a needle valve to ensure a slow and steady stream of argon through the reaction solution. Toluene $(80 \mathrm{~mL})$ and diethyldiallylmalonate $(4.0 \mathrm{~g}, 16.8 \mathrm{mmol})$ were added to the reaction vessel and the reaction was heated to $50{ }^{\circ} \mathrm{C}$. Complex $6(7.0 \mathrm{mg}, 0.01$ mmol) was weighed into a custom-made aluminum weighing tray and added to the reaction mixture. Samples were taken at regular intervals via syringe through the septum. Samples were analysed by GC with a Pona column.

Ethenolysis of Methyl Oleate (Representative Procedure): Methyl oleate (99\%) was purchased from Aldrich and passed through a short $(2 \mathrm{~cm})$ pad of alumina before use. In a $50 \mathrm{~mL}$ stainless-steel autoclave fitted with dip-tube for sampling was charged methyl oleate (12 g, $40.0 \mathrm{mmol})$. Tetradecane (2.5 g, internal standard) was added and the catalyst $(0.010 \mathrm{mmol})$ was weighed and transferred into a Schlenk flask under argon. Toluene (5 mL, degassed) was added to the Schlenk flask and an aliquot (1 $\mathrm{mL}$ ) of this stock solution was transferred to the autoclave. The autoclave was pressurized (4-20 bar of ethylene) and heated via computerized temperature controller to the desired temperature. Samples were taken at regular intervals using a dip-tube apparatus, and analyzed by GC with an MDN column.

CM of 1-Dodecene with Styrene (Representative Procedure): A $25 \mathrm{~mL}$ three-necked round bottom flask was fitted with a reflux condenser, thermometer and septum. A needle was inserted through the septum and connected to a gas supply via a needle valve to ensure a slow and steady stream of argon through the reaction solution. Styrene $(2.3 \mathrm{~mL}, 25.5 \mathrm{mmol})$ and 1-dodecene $(1.5 \mathrm{~mL}, 7.75$ mmol) was added to the reaction vessel and the reaction was heated to $50{ }^{\circ} \mathrm{C}$. Complex $6(13.3 \mathrm{mg}$, $0.0194 \mathrm{mmol}$ ) was weighed into a custom-made aluminum weighing tray and added to the reaction mixture. Samples were taken at regular intervals via syringe through the septum. Samples were analysed by GC with a Pona column and by GCMS with an MDN column. 
CM of 1-Dodecene with 5-Hexene-2-one (Representative Procedure): A $25 \mathrm{~mL}$ three-necked round bottom flask was fitted with a dry-ice reflux condenser, thermometer and septum. A needle was inserted through the septum and connected to a gas supply via a needle valve to ensure a slow and steady stream of argon through the reaction solution. 5-Hexene-2-one $(2.7 \mathrm{~mL}, 25.5 \mathrm{mmol})$ and 1 dodecene $(1.5 \mathrm{~mL}, 7.75 \mathrm{mmol})$ was added to the reaction vessel and the reaction was heated to $50{ }^{\circ} \mathrm{C}$. Complex 6 (37 mg, $0.039 \mathrm{mmol})$ was weighed into a custom-made aluminum weighing tray and added to the reaction mixture. Samples were taken at regular intervals via syringe through the septum. Samples were analysed by GC with a Pona column and by GCMS with an MDN column.

CM of 3,3-Dimethyl-1-butene with 4-Hexen-1-yl acetate (Representative Procedure): A 25 $\mathrm{mL}$ three-necked round bottom flask was fitted with a dry-ice reflux condenser, thermometer and septum. A needle was inserted through the septum and connected to a gas supply via a needle valve to ensure a slow and steady stream of argon through the reaction solution. 4-Hexen-1-yl acetate $(2.5 \mathrm{~g}$, $17.6 \mathrm{mmol})$ and 3,3-Dimethyl-1-butene (6 $\mathrm{mL}$, excess) was added to the reaction vessel and the reaction was heated to reflux $\left(41^{\circ} \mathrm{C}\right)$. Complex $6(120 \mathrm{mg}, 0.175 \mathrm{mmol})$ was weighed into a custommade aluminum weighing tray and added to the reaction mixture. Samples were taken at regular intervals via syringe through the septum. Samples were analysed by GC with a Pona column and by GCMS with an MDN column.

Treatment of 5 with $\mathbf{H C l}$ : In a $10 \mathrm{~mL}$ schlenk flask was weighed out ca. $30 \mathrm{mg}$ of 5. An $\mathrm{HCl}$ solution ( $3 \mathrm{~mL}$ of a $2 \mathrm{M}$ soln in $\mathrm{Et}_{2} \mathrm{O}$ ) was added, and the purple solution stirred for 10 minutes. After such time the solvent was removed under vacuum. $\mathrm{A}{ }^{31} \mathrm{P}\left({ }^{1} \mathrm{H}\right) \mathrm{NMR}\left(121 \mathrm{MHz}, \mathrm{CD}_{2} \mathrm{Cl}_{2}\right)$ showed unchanged $5(\delta=24.5(\mathrm{bs}))$. In a separate experiment, the same experiment was performed for catalyst 1: Thus, In a $10 \mathrm{~mL}$ schlenk flask was weighed out ca. $30 \mathrm{mg}$ of $\mathbf{1}$. An $\mathrm{HCl}$ solution (3 mL of a $2 \mathrm{M}$ soln in $\mathrm{Et}_{2} \mathrm{O}$ ) was added, and the solution instantly turned green, which gave no identifiable products by ${ }^{31} \mathrm{P}$ or ${ }^{1} \mathrm{H}$ NMR. 
Thermal Decomposition of $(\mathbf{P h o b C y})_{2} \mathbf{C l}_{2} \mathbf{R u}=\mathbf{C D}_{2}$ (9): In a glovebox was weighed complex 9 (ca. $30 \mathrm{mg}$ ) and transferred to an NMR tube. Dry, degassed toluene was added and the NMR tube sealed. The NMR tube was removed from the glovebox and placed in a Varian Unity Plus $500 \mathrm{MHz}$ spectrometer which was preheated to $50{ }^{\circ} \mathrm{C} .{ }^{2} \mathrm{H}$ NMR Spectra were initially taken at 20 minute intervals for the first 2 hours, then at 30 minute intervals thereafter and were referenced against an internal benzene standard $(\delta=7.16 \mathrm{ppm})$. The spectrum below shows the thermal decomposition after 20 minutes at $50{ }^{\circ} \mathrm{C}$. From left to right: $(\mathrm{PhobCy})_{2} \mathrm{Cl}_{2} \mathrm{Ru}=\mathrm{CD}_{2}$ carbene signal $(\delta=19.2 \mathrm{ppm})$, internal benzene standard $(\delta=7.16 \mathrm{ppm}), \mathrm{D}_{2} \mathrm{C}=\mathrm{CD}_{2}(\delta=5.25 \mathrm{ppm})$ and aliphatic $\mathrm{D}$ resonances. In a separate experiment, $\mathrm{D}_{2} \mathrm{C}=\mathrm{CD}_{2}$ was bubbled through a toluene solution containing internal benzene standard, and a ${ }^{2} \mathrm{H}$ NMR spectrum taken. A single resonance at $\delta=5.25 \mathrm{ppm}$ was observed.

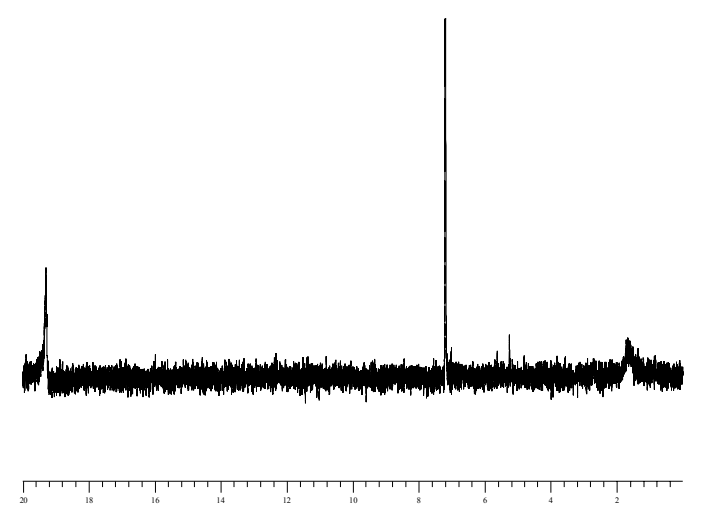

Thermal Decomposition of (PhobCy) $\mathbf{C l}_{2} \mathbf{R u}=\mathrm{CH}_{2}(\mathbf{1 0})$ : In a glovebox was weighed complex $10(10 \mathrm{mg}, 0.014 \mathrm{mmol})$ and transferred to an NMR tube. Dry, degassed benzene- $d_{6}(0.7 \mathrm{~mL})$ was added and the NMR tube sealed. The NMR tube was removed from the glovebox and placed in a Varian Unity Plus $500 \mathrm{MHz}$ spectrometer which was preheated to $70{ }^{\circ} \mathrm{C} .{ }^{31} \mathrm{P}$ NMR Spectra were initially taken at 5 minute intervals and were referenced against an external $\mathrm{H}_{3} \mathrm{PO}_{4}(\delta=0 \mathrm{ppm})$ standard. The graph below shows the relative integral of the methylidene signal in the ${ }^{31} \mathrm{P}$ NMR spectrum against the internal standard as a function of time. 


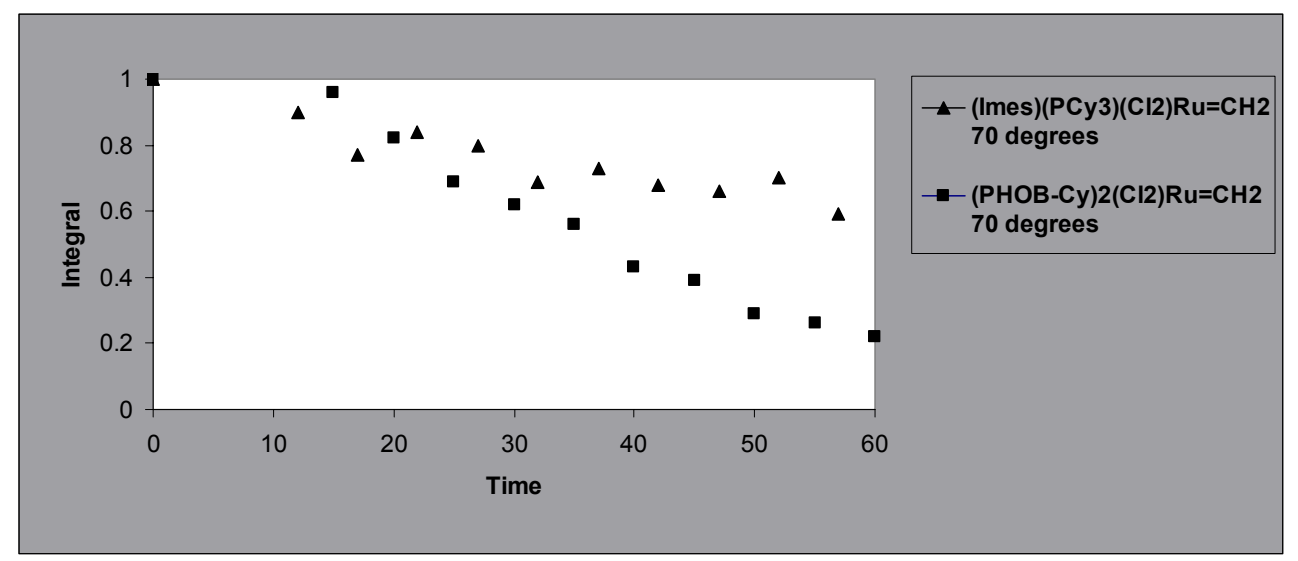

\section{References}

(1) Amoroso, D.; Snelgrove, J. L.; Conrad, J. C.; Drouin, S. D.; Yap, G. P. A.; Fogg, D. E. $A d v$. Synth. Catal. 2002, 344, 757-763. 